\title{
High protein and cholesterol intakes associated with emergence of glucose intolerance in a low-risk Canadian Invit population
}

\author{
Saghar Sefidbakht ${ }^{1}$, Louise Johnson-Down ${ }^{1}$, T Kue Young $^{2}$ and Grace M Egeland ${ }^{1,3, *}$ \\ 'School of Dietetics and Human Nutrition and Centre for Indigenous Peoples' Nutrition and Environment (CINE), \\ McGill University, Montreal, Canada: ${ }^{2}$ School of Public Health, University of Alberta, Edmonton, Canada: \\ ${ }^{3}$ Department of Global Public Health and Primary Care, Faculty of Medicine and Dentistry, University of Bergen, and \\ Norwegian Institute of Public Health, Kalfarveien 31, 5018 Bergen, Norway
}

Submitted 16 April 2015: Final revision received 23 June 2015: Accepted 23 September 2015: First published online 23 October 2015

\begin{abstract}
Objective: The rate of type 2 diabetes mellitus among Inuit is $12.2 \%$ in individuals over 50 years of age, similar to the Canadian prevalence. Given marked dietary transitions in the Arctic, we evaluated the dietary and other correlates of not previously diagnosed glucose intolerance, defined as type 2 diabetes mellitus, impaired fasting glucose or impaired glucose tolerance.

Design: Cross-sectional analyses were limited to adults with a completed $2 \mathrm{~h}$ oral glucose tolerance test and without pre-existing diabetes. Anthropometric assessments, health and medication usage questionnaires and a $24 \mathrm{~h}$ dietary recall were administered.

Setting: Canadian International Polar Year Inuit Health Survey (2007-2008).

Subjects: Inuit adults ( $n$ 777).

Results: Glucose intolerance was associated with older age and adiposity. Percentage of energy from protein above the Acceptable Macronutrient Distribution Range of $35 \%$, compared with intake within the range, was associated with increased odds of glucose intolerance $(\mathrm{OR}=1.98 ; 95 \%$ CI 1.09, 3.61) in multivariable analyses. Further, cholesterol intake in the highest three quartiles combined (median exposures of 207, 416 and $778 \mathrm{mg} / \mathrm{d}$, respectively) compared with the lowest quartile (median intake of $81 \mathrm{mg} / \mathrm{d}$ ) was associated with glucose intolerance (OR $=2 \cdot 15$; $95 \%$ CI $1 \cdot 23,3 \cdot 78)$ in multivariable analyses. Past-day traditional food consumption was borderline protective of glucose intolerance $(P=0.054)$ and high fibre intake was not significantly protective $(P=0 \cdot 08)$.

Conclusions: The results contribute to the existing literature on high protein and cholesterol intakes as they may relate to diabetes risk.
\end{abstract}

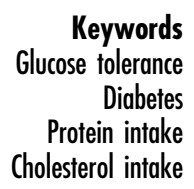

The prevalence of type 2 diabetes mellitus (DM) was historically rare among Inuit ${ }^{(1)}$ but there is evidence that the prevalence is increasing ${ }^{(2,3)}$, raising concerns that Inuit may face a future epidemic in type $2 \mathrm{DM}$ as experienced by other Indigenous Peoples decades ago ${ }^{(4)}$. The traditional diet of Arctic Indigenous Peoples is remarkably high in fat, yet the marine sources of fatty acids are thought to contribute to the historically low prevalence of chronic diseases observed in this population ${ }^{(5)}$. Similarly, a study of Canadian Inuit found that while the consumption of traditional food (TF) was high, $66 \%$ of the energy in the diet came from market foods, with the top contributors to energy intake (EI) being refined carbohydrates, bannock (a traditional biscuit), table sugar, cookies and soft drinks ${ }^{(6)}$. Inuit $\mathrm{TF}$ include marine mammals, game meat, birds, berries and seaweed; foods are traditionally eaten raw.

Lifestyle changes associated with Westernization have increased the prevalence of certain chronic diseases, including obesity, CVD and type $2 \mathrm{DM}^{(7,8)}$. The nutrition transition in the Arctic coexists with a high prevalence of food insecurity. This represents a dual burden on the population of possible poor diet quality with potential long-term consequences for emergence of diet-related chronic diseases $^{(9)}$. Thus, the goal of the current study was to evaluate selected dietary exposures associated with newly ascertained glucose intolerance among Inuit of Canada. Dietary analyses focused upon evaluation of

*Corresponding author: Email g.egeland@uib.no

(C) The Authors 2015. This is an Open Access article, distributed under the terms of the Creative Commons Attribution licence (http://creativecommons.org/licenses/by/4.0/), which permits unrestricted re-use, distribution, and reproduction in any medium, provided the original work is properly cited. 
macronutrient intakes and cholesterol, saturated fat, Zn, $\mathrm{Mg}$, fibre and high-sugar beverage consumption given the literature implicating these exposures for development of type $2 \mathrm{DM}^{(10-18)}$.

\section{Methods}

A cross-sectional Canadian International Polar Year Inuit Health Survey was conducted in three jurisdictions (Inuvialuit Settlement Region of Northwest Territories, Nunavut Territory and Nunatsiavut region in Labrador) in 2007 and $2008^{(2,9)}$. Households were randomly selected through randomization of community housing maps and lists and Inuit adults, 18 years of age or older, were invited to participate in the survey. A total of 2796 Inuit households were successfully visited by community research assistants and 1901 (68.0\%) households participated in the survey, with an average of 1.38 participants per household ( $n$ 2595). Due to survey logistical constraints, approximately $30 \%$ of survey participants had a $75 \mathrm{~g}, 2 \mathrm{~h}$ oral glucose tolerance test (OGTT) either on board the Canadian Coast Guard Ship CCGS Amundsen which assisted the research in thirty-three coastal communities or at clinic sites in three land-based surveys for inland communities. Thus, of the original 2595 adults who participated in the survey, only those with a completed OGTT and without pre-existing diagnosed diabetes, as identified by medication or dietary treatments, were included in the present analyses ( $n$ 777).

The results from the fasting and the OGTT were used to classify participants as glucose intolerant or normoglycaemic, where glucose intolerant included those with impaired fasting glucose or impaired glucose tolerance or diabetes based upon American Diabetes Association criteria $^{(19)}$. Fasting $(>7.5 \mathrm{~h})$ venous blood samples were collected and kept cool before being centrifuged and frozen at $-80^{\circ} \mathrm{C}$ until later analyses of plasma glucose assessed by the Glucose Hexokinase II method ${ }^{(20)}$, handled by Nutrasource Diagnostics (Guelph, Ontario, Canada).

Nurses conducted anthropometric assessments in which participants removed shoes and wore light clothing; weight and percentage body fat $(\% \mathrm{BF})$ were measured using a Tanita foot-to-foot bioelectrical impedance scale (TBF-300A; Tanita Corp, Arlington Heights, IL, USA) and height with a portable stadiometer (Road Rod 214 Portable Stadiometer; Seca, Hanover, MD, USA). BMI was calculated as $\mathrm{kg} / \mathrm{m}^{2}$ where $\mathrm{BMI}=25 \cdot 0-29 \cdot 9 \mathrm{~kg} / \mathrm{m}^{2}$ was considered overweight and $\mathrm{BMI} \geq 30 \mathrm{~kg} / \mathrm{m}^{2}$ was considered obese according to WHO criteria ${ }^{(21)}$. At-risk waist circumference (WC $\geq 102 \mathrm{~cm}$ in men, WC $\geq 88 \mathrm{~cm}$ in women $)^{(22)}$ and at-risk $\% \mathrm{BF}(\% \mathrm{BF} \geq 25$ for men, $\% \mathrm{BF} \geq 31$ for women) ${ }^{(23)}$ were defined using existing guidelines. BMR was calculated by the Tanita scale using fat-free mass (FFM) and the US prediction formula, which was cross-validated in a Japanese population: REE $(\mathrm{kcal} / \mathrm{d})=20 \cdot 5 \times \mathrm{FFM}(\mathrm{kg})+$ $462^{(24)}$ (where $\mathrm{REE}=$ resting energy expenditure).
Nurses assessed health histories and medication usage, whereas trained bilingual Inuit- and English-language interviewers administered sociodemographic and physical activity questionnaires and a dietary assessment which included a $24 \mathrm{~h}$ dietary recall using food portion model kits (Santé Québec, Québec, Canada). A short version of the International Physical Activity Questionnaire was used to calculate each participant's physical activity score in MET-min/week ${ }^{(25)}$ (where MET = metabolic equivalents of task).

Dietary variables based upon the $24 \mathrm{~h}$ recalls that were examined included: percentage of energy (\%E) from macronutrients, \%E from saturated fat, \%E from $\mathrm{TF}$, high-sugar drinks (i.e. greater than $25 \%$ of total sugar excluding fruit juices; yes $v$. no) and selected dietary factors postulated to be related to type $2 \mathrm{DM}$ risk, i.e. fibre, cholesterol, $\mathrm{Zn}$ and $\mathrm{Mg}^{(26)}$. The 2007b Canadian Nutrient File was used to estimate the nutrient intakes ${ }^{(27)}$. The Canadian Nutrient File does not contain data on glycaemic index of food items and its trans-fat updates lag behind the rapid market transitions in product trans-fat content. Thus, glycaemic index and trans-fat intake were not evaluated in our analyses. TF included local food items that are typically and traditionally harvested in the Arctic including marine and land mammals, fish and seafood, berries and plants including seaweed.

\section{Statistical analysis}

The $\chi^{2}$ test was conducted to evaluate differences in demographic characteristics between those with and without glucose intolerance in analyses stratified by sex. Differences in mean dietary exposures between those with and without glucose intolerance were evaluated using the $t$ test and results are presented as means with standard deviations. Multivariable logistic regression analyses reporting odds ratios and 95\% confidence intervals were conducted, where the outcome was glucose intolerance (yes $v$. no) and independent variables such as dietary factors, demographic covariates (with tests for sex interactions) and medication usage that could influence glucose intolerance were included. As covariate by sex interaction terms were not significant they were not included in the final models presented. Variables that either were associated with glucose intolerance or changed the beta coefficient of a dietary exposure variable by more than $10 \%$ were retained in multivariable models as covariates. Also, total EI was controlled for in the logistic regressions when evaluating the past-day nutrient intakes such as fibre (g/d), Mg, Zn and cholesterol (mg/d). Macronutrient and TF intakes were evaluated in regression analyses using the nutrient density approach as \%E, to control for EI which varies substantially between individuals ${ }^{(28)}$. As certain antihypertensive medications can influence glucose values, the use of antihypertensive medications was entered as a covariate in all multivariable analyses ${ }^{(29)}$. Regional differences in the degree of acculturation exist in the Arctic; we therefore 
also adjusted for region (Nunavut, Nunatsiavut and Inuvialuit Settlement Region) in all multivariable analyses.

Further, to evaluate the extent of under-reporting of EI by participants and whether the extent of underreporting varied by glucose intolerance status, EI:BMR was calculated where a ratio under 1.52 was considered an indication of under-reporting based upon methodology described elsewhere ${ }^{(30)}$. Macronutrients were assessed as quartiles of $\% \mathrm{E}$ and in categories representing above, within and below the Acceptable Macronutrient Distribution Range (AMDR) ${ }^{(31)}$. Quartile groups of dietary intake variables were determined and tests for trend were conducted by logistic regression where the median intake level of each quartile group was the independent variable. Because the majority of participants consumed low amounts of fibre and excessive amounts of cholesterol, these dietary variables were consolidated into two categories representing high and low intakes. For fibre, the highest quartile (median intake of $19 \mathrm{~g} / \mathrm{d}$ ) was contrasted against the lowest three quartiles combined (median intakes of $2.6,6.5$ and $10.9 \mathrm{~g} / \mathrm{d}$, respectively). For cholesterol, the highest three quartiles (median intakes of 207, 416 and $778 \mathrm{mg} / \mathrm{d}$ ) were combined into one high cholesterol intake group and contrasted against the lowest quartile (median of $81 \mathrm{mg} / \mathrm{d}$ ). The diagnostic tests (variance inflation factors and condition indices) for collinearity evaluated the suitability of the final multivariable models presented.

Statistical analyses were conducted using the statistical software package STATA version 11.2. Given that more than one person per household could participate, household was entered as a cluster variable in all multivariable analyses. Two-sided tests were conducted in all analyses and $P<0.05$ was considered statistically significant.

\section{Results}

\section{Unadjusted analyses of demographic and dietary characteristics}

A total of 306 males and 471 females completed the OGTT and the dietary data. The mean age of the men and women included in the present analyses was $42 \cdot 2$ (SD 13.9) years and 41.0 (SD 13.4) years, respectively. The 137 participants with glucose intolerance included six with potential diabetes, eighty-nine with impaired fasting glucose, fifty-two with impaired glucose tolerance, with ten having both impaired fasting and impaired glucose tolerance. The prevalence of glucose intolerance was similar for men (18.6\%) and women $(17.0 \%)$ despite significant sex differences in the prevalence of risk factors, where women compared with men were more likely to be obese $(44.6 \% v$. $27.7 \%$; $P<0.05)$, have an at-risk WC $(63.7 \% v .27 .8 \% ; P<0.05)$ and have an at-risk $\% \mathrm{BF}(68.9 \% v .40 .6 \% ; P<0.05)$. Conversely, women had lower mean physical activity scores (3180 (SD 3637) MET-min/week) than men (5464 (SD 5105)
MET-min/week; $P<0.05)$ and smoked fewer cigarettes $(10.5$ (SD 6.65) per $\mathrm{d}$ ) than men (12.2 (sD 7.90) per $\mathrm{d} ; P<0.05)$.

In analyses of the percentage of glucose intolerance by categories of risk factors, a striking age gradient in risk for glucose intolerance was noted for men and women (Table 1). Likewise, a greater risk of glucose intolerance was noted among those classified with high BMI, \%BF and WC. Those with less than a high school education and those reporting no alcohol drinking had a greater prevalence of glucose intolerance relative to those with a higher level of education and those reporting any alcohol consumption. Alcohol consumption was $8.59 \mathrm{~g} / \mathrm{d}$ for consumers and $5.68 \mathrm{~g} / \mathrm{d}$ for the total sample. Smokers had a lower prevalence of glucose intolerance than non-smokers. Family history of diabetes was missing for $25.0 \%$ of men and $22.7 \%$ of women; the percentage of glucose intolerance tended to be higher among those either reporting a family history of diabetes or missing information on family history, with significant group differences noted for men (Table 1).

Table 1 Percentage of glucose intolerance by demographic characteristics and sex; Inuit adults ( $n 777$ ), Canada (International Polar Year Inuit Health Survey 2007-2008)

\begin{tabular}{|c|c|c|c|c|}
\hline \multirow[b]{2}{*}{ Characteristic } & \multicolumn{2}{|r|}{ Men } & \multicolumn{2}{|r|}{ Women } \\
\hline & $n$ & $\begin{array}{l}\% \text { glucose } \\
\text { intolerance }\end{array}$ & $n$ & $\begin{array}{l}\% \text { glucose } \\
\text { intolerance }\end{array}$ \\
\hline \multicolumn{5}{|l|}{ Region } \\
\hline Nunavut & 212 & $17 \cdot 5$ & 314 & $17 \cdot 2$ \\
\hline Inuvialuit & 49 & $28 \cdot 6$ & 94 & 14.9 \\
\hline Nunatsiavut & 45 & $13 \cdot 3$ & 63 & $19 \cdot 1$ \\
\hline \multicolumn{5}{|l|}{ Age } \\
\hline$<30$ years & 64 & $3 \cdot 1$ & 107 & $3 \cdot 7^{\star}$ \\
\hline $30-40$ years & 72 & $12 \cdot 5$ & 105 & 11.4 \\
\hline$>40-60$ years & 130 & $22 \cdot 3$ & 216 & $20 \cdot 4$ \\
\hline$>60$ years & 40 & 42.5 & 43 & $46 \cdot 5$ \\
\hline \multicolumn{5}{|l|}{ Smoking } \\
\hline Yes & 201 & $14.9^{*}$ & 325 & $11 \cdot 7^{*}$ \\
\hline No & 104 & $25 \cdot 0$ & 146 & 28.8 \\
\hline \multicolumn{5}{|l|}{ BMI $\left(\mathrm{kg} / \mathrm{m}^{2}\right)$} \\
\hline$<30.0$ & 226 & $13 \cdot 3^{*}$ & 260 & $10 \cdot 0^{*}$ \\
\hline$\geq 30.0$ & 80 & 33.8 & 209 & $25 \cdot 4$ \\
\hline \multicolumn{5}{|l|}{$\% \mathrm{BF}+$} \\
\hline Low & 180 & $11 \cdot 1^{*}$ & 145 & $7 \cdot 6^{*}$ \\
\hline High & 123 & $30 \cdot 1^{*}$ & 321 & $20 \cdot 9^{*}$ \\
\hline \multicolumn{5}{|l|}{ WCF } \\
\hline Low & 218 & $11 \cdot 5^{\star}$ & 169 & $9 \cdot 5^{\star}$ \\
\hline High & 88 & 37.5 & 303 & $22 \cdot 1$ \\
\hline \multicolumn{5}{|l|}{ Alcohol } \\
\hline Yes & 198 & $14 \cdot 7^{*}$ & 276 & $11 \cdot 6^{*}$ \\
\hline No & 92 & $25 \cdot 0$ & 174 & $24 \cdot 1$ \\
\hline \multicolumn{5}{|l|}{ Education } \\
\hline$<$ High school & 57 & $28 \cdot 1^{*}$ & 74 & $31 \cdot 1^{*}$ \\
\hline$\geq$ High school & 246 & $16 \cdot 3$ & 396 & 14.4 \\
\hline \multicolumn{5}{|c|}{ Family history of diabetes } \\
\hline Yes & 36 & $27 \cdot 8^{*}$ & 90 & $20 \cdot 0$ \\
\hline No & 193 & 13.5 & 274 & $14 \cdot 6$ \\
\hline Missing & 77 & $27 \cdot 3$ & 107 & $20 \cdot 6$ \\
\hline
\end{tabular}

$\% B F$, percentage body fat; WC, waist circumference.

*Percentage of glucose intolerance was significantly different by characteristic in analyses conducted separately for men and women $\left(X^{2}\right.$ test): $P<0.05$. †High \%BF: \%BF $\geq 31$ for women and \%BF $\geq 25$ for men.

fHigh WC: $W C \geq 88 \mathrm{~cm}$ for women and $W C \geq 102 \mathrm{~cm}$ for men 
Men reported a total EI of 10732 (SD 6498) kJ/d and women reported a total EI of 8816 (sD 4376) kJ/d. Values of EI:BMR indicated that participants were mildly under-reporting EI (EI:BMR $=1.48$ (SD 0.93) and 1.47 (SD 0.77 ) for men and women, respectively). For men, median total EI was 8887 (interquartile range (IQR) 5046-11 715) $\mathrm{kJ} / \mathrm{d}$ and 9824 (IQR 6251-14 548) kJ/d for those with and without glucose intolerance, respectively. For women, median total EI was 7590 (IQR 5510-10 652) kJ/d and 8226 (IQR 6046-11 129) kJ/d for those with and without glucose intolerance, respectively.

\section{Multivariable analyses}

In a multivariable logistic regression model entering all statistically significant demographic characteristics, age and WC remained significantly associated with glucose intolerance, whereas smoking, alcohol, family history of type $2 \mathrm{DM}$ and education were no longer associated with glucose intolerance (data not shown). In separate analysis of each macronutrient, adjusting for age, sex, WC, region and use of antihypertensive medications, \% $\mathrm{E}$ from carbohydrate below the AMDR of $45 \%$ was associated with significant excess risk of glucose intolerance (Table 2). For cholesterol, intake in quartiles 2, 3 and 4 (median intakes of 207, 416 and $778 \mathrm{mg} / \mathrm{d}$, respectively) was associated with a higher risk of glucose intolerance relative to those in the lowest quartile of intake (median $81.0 \mathrm{mg} / \mathrm{d}$; Table 2). Further, a test for trend entering median cholesterol intake for each quartile was significant $(P=0 \cdot 00)$. No other associations or trends were observed for the other nutrients.

In further multivariable logistic regression analyses controlling for age, sex, WC, region and use of antihypertensive medications, and simultaneously entering dietary variables, $\% \mathrm{E}$ from protein above the AMDR $v$. within the AMDR and cholesterol intake in the highest three quartiles combined $v$. the lowest quartile were associated with higher glucose intolerance (Table 3). The result for fibre intake in the highest quartile $v$. the lowest three quartiles combined was not significant $(P=0.08)$ and any TF consumption in the past day was marginally significant $(P=0.054)$, but both were suggestive of a tendency for a lower odds of glucose intolerance (Table 3, model 1).

In analyses where we substituted \%E from protein with $\% \mathrm{E}$ from carbohydrate, we found that \%E from carbohydrate above $v$. below the AMDR was not associated with glucose intolerance (Table 3, model 2). As \%E from protein and \%E from carbohydrate were highly and inversely correlated, the variables were not considered together in any multivariable analyses.

Table 2 Dietary factors evaluated separately in multiple logistic regression analyses for their association with glucose intolerance; Inuit adults ( $n$ 777), Canada (International Polar Year Inuit Health Survey 2007-2008)

\begin{tabular}{|c|c|c|c|}
\hline Variable & Category & Adjusted OR & $95 \% \mathrm{Cl}$ \\
\hline \multirow[t]{3}{*}{$\%$ E from protein $†$} & AMDR (10-35\%) & Referent & \\
\hline & $<$ AMDR & 0.46 & $0.17,1.28$ \\
\hline & $>$ AMDR & 1.76 & $0.99,3.13$ \\
\hline \multirow[t]{3}{*}{$\%$ E from fat $†$} & AMDR $(20-35 \%)$ & Referent & \\
\hline & $<$ AMDR & 1.22 & $0.60,2.49$ \\
\hline & >AMDR & 0.93 & $0.61,1.43$ \\
\hline \multirow[t]{3}{*}{$\% \mathrm{E}$ from carbohydrate† } & AMDR (45-65\%) & Referent & \\
\hline & $<$ AMDR & $1.62^{*}$ & $1.03,2.56$ \\
\hline & $>$ AMDR & 1.42 & $0.62,3.24$ \\
\hline \multirow[t]{2}{*}{$\%$ E from saturated fat† } & Recommendation (<10\%) & Referent & \\
\hline & >Recommendation & 1.44 & $0.97,2.13$ \\
\hline \multirow[t]{3}{*}{$\%$ E from TF† } & $\mathrm{T} 1($ median $=0)$ & Referent & \\
\hline & T2 $($ median $=10.4)$ & 0.90 & $0.51,1.58$ \\
\hline & T3 $($ median $=38.6)$ & 0.77 & $0.46,1.29$ \\
\hline \multirow[t]{4}{*}{ Cholesterol $(\mathrm{mg} / \mathrm{d}) \ddagger$} & Q1 $($ median $=81.0)$ & Referent & \\
\hline & Q2 (median = 207) & $2 \cdot 10^{\star}$ & $1.07,4.11$ \\
\hline & Q3 $($ median $=416)$ & $2 \cdot 87^{*}$ & $1.46,5.63$ \\
\hline & Q4 $($ median $=778)$ & $3 \cdot 17^{*}$ & $1.60,6.27$ \\
\hline \multirow[t]{4}{*}{ Fibre $(g / d) \ddagger$} & Q1 $($ median $=2.64)$ & Referent & \\
\hline & Q2 (median $=6.45)$ & 0.89 & $0.51,1.57$ \\
\hline & Q3 (median = 10.9) & 0.93 & $0.52,1.67$ \\
\hline & Q4 $($ median $=19.0)$ & 0.58 & $0.28,1.16$ \\
\hline \multirow[t]{4}{*}{$M g(g / d) \ddagger$} & Q1 $($ median $=117)$ & Referent & \\
\hline & Q2 $($ median $=190)$ & $1 \cdot 13$ & $0.62,2.05$ \\
\hline & Q3 $($ median $=268)$ & 1.51 & $0.80,2.85$ \\
\hline & Q4 (median $=426)$ & 1.58 & $0.69,3.61$ \\
\hline \multirow{2}{*}{ High-sugar drinks† } & No & Referent & \\
\hline & Yes & 0.92 & $0.58,1.46$ \\
\hline
\end{tabular}

\%E, percentage of energy; TF, traditional food; AMDR, Acceptable Macronutrient Distribution Range ${ }^{(31)}$; T, tertile; $Q$, quartile.

${ }^{*}$ Significant OR and $95 \% \mathrm{Cl}: P<0.05$.

†Model includes each dietary variable separately with age, sex, waist circumference, region and antihypertensive medication usage, with household entered as a cluster variable.

¥Model includes each dietary variable separately with model 1 variables plus total energy intake. 
Table 3 Dietary associates of glucose intolerance in multivariable logistic regression analyses considering demographic and dietary variables simultaneously; Inuit adults ( $n 777$ ), Canada (International Polar Year Inuit Health Survey, 2007-2008)

\begin{tabular}{|c|c|c|c|c|}
\hline Variable & Category & Adjusted OR & $95 \% \mathrm{Cl}$ & $P$ \\
\hline \multicolumn{5}{|l|}{ Model 1† } \\
\hline \multirow[t]{3}{*}{$\% \mathrm{E}$ from protein } & AMDR (10-35\%) & Referent & & \\
\hline & $<$ AMDR & 0.57 & $0.20,1.61$ & 0.28 \\
\hline & >AMDR & 1.98 & $1.09,3.61$ & 0.03 \\
\hline \multirow{2}{*}{ Cholesterol (mg/d) } & Q1 & Referent & & \\
\hline & Q2-Q4 & $2 \cdot 15$ & $1 \cdot 23,3 \cdot 78$ & 0.01 \\
\hline \multirow[t]{2}{*}{ Fibre $(g / d)$} & Q1-Q3 & Referent & & \\
\hline & Q4 & 0.61 & $0.35,1.06$ & 0.08 \\
\hline \multirow[t]{2}{*}{$\%$ from TF } & T1 (none) & Referent & & \\
\hline & T2-T3 (any) & 0.61 & $0.37,1.01$ & 0.05 \\
\hline \multirow[t]{2}{*}{ High-sugar drinks } & No & Referent & & \\
\hline & Yes & 1.43 & $0.91,2.26$ & 0.12 \\
\hline \multicolumn{5}{|l|}{ Model $2 \dagger$} \\
\hline \multirow[t]{3}{*}{$\%$ E from carbohydrate } & AMDR (45-65\%) & Referent & & \\
\hline & $<$ AMDR & 1.57 & $0.96,2.56$ & 0.07 \\
\hline & $>$ AMDR & 1.71 & $0.72,4.08$ & 0.22 \\
\hline \multirow{2}{*}{ Cholesterol (mg/d) } & Q1 & Referent & & \\
\hline & Q2-Q4 & 2.35 & $1 \cdot 27,4 \cdot 35$ & 0.01 \\
\hline \multirow[t]{2}{*}{ Fibre $(g / d)$} & Q1-Q3 & Referent & & \\
\hline & Q4 & 0.62 & $0.35,1.08$ & 0.09 \\
\hline \multirow[t]{2}{*}{$\%$ from TF } & T1 (none) & Referent & & \\
\hline & T2-T3 (any) & 0.69 & $0.43,1.12$ & 0.13 \\
\hline \multirow[t]{2}{*}{ High-sugar drinks } & No & Referent & & \\
\hline & Yes & 1.45 & $0.91,2 \cdot 30$ & 0.11 \\
\hline
\end{tabular}

$\%$ E, percentage of energy; TF, traditional food; AMDR, Acceptable Macronutrient Distribution Range ${ }^{(31)}$; Q, quartile; T, tertile. †Multivariable models include all dietary variables listed under model 1 and model 2 and age, sex, waist circumference, antihypertensive medication usage and region, with household entered as a cluster variable.

All multivariable analyses presented in Tables 2 and 3 were evaluated with additional adjustment for family history of diabetes, smoking, education and alcohol consumption. These additional analyses identified no changes (by more than 10\%) to the beta coefficients presented in Tables 2 and 3. Model 1 was also run with \%E from fat but this variable did not contribute significantly to the model and the covariates did not change by more than $10 \%$ as compared with the other models in Table 3.

\section{Discussion}

The dietary findings agree with the literature on dietary risk factors for type $2 \mathrm{DM}$ and they add to our understanding of the nutritional transition that may be important in a population undergoing rapid acculturation.

Dietary characteristics emerged as significant determinants of glucose intolerance in the current cross-sectional health survey. Our findings suggest that high protein and low carbohydrate intakes were associated with greater risk for glucose intolerance. Further, we found a significant test for trend for cholesterol intake in our study population, similar to the Iowa Women's Health Study in which the highest quintile of cholesterol intake (median of $382 \mathrm{mg} / \mathrm{d}$ ) was associated with increased risk of incident diabetes in postmenopausal women ${ }^{(26)}$. In contrast to the Iowa Women's Health Study, the intake of dietary cholesterol was excessively high in the current Inuit study population.
While cholesterol intake is a risk factor for CVD, its importance in the aetiology of diabetes is not yet established and additional research in this area is warranted.

Our findings are similar to those of the high-risk Sandy Lake Cree of Ontario, Canada in which high protein and low carbohydrate intakes were significantly related to newly identified type $2 \mathrm{DM}^{(14)}$. Currently, the existing literature on protein intake and glucose metabolism is inconsistent: a high protein intake, in the short term, may improve glucose metabolism ${ }^{(32)}$, but in the Health Professionals Follow-Up Study, high animal protein and fat intakes were associated with an increased risk of diabetes, findings which were attributed to red and processed meat ${ }^{(10)}$. In the Women's Health Initiative, higher protein and energy intakes were associated with the development of diabetes ${ }^{(33)}$. In the European Prospective Investigation into Cancer and Nutrition, risk of type 2 DM was higher with higher protein intakes, especially animal protein ${ }^{(34)}$. The Alpha-Tocopherol, Beta-Carotene Cancer Prevention Study reported high processed meat consumption was a risk factor for type $2 \mathrm{DM}^{(35)}$. Haem Fe intake was positively related to type $2 \mathrm{DM}$ in the Nurses' Health Study, in the Iowa Women's Health Study and in Mediterranean and Chinese cohorts ${ }^{(36-39)}$. However, TF such as marine mammals and game are rich in haem Fe and therefore not a likely candidate for explaining the associations observed in our study population, as we identified an almost significant beneficial association between past-day $\mathrm{TF}$ consumption and glucose intolerance. 
Also, while more work is needed to identify mechanisms, the emerging literature linking dietary exposures to gut microbiota is a promising area of research. In rats, the amount of total protein rather than the source has been identified as an important determinant of the degree of protein fermentation in the gut, with implications for both the presence of toxic fermentation by-products and the bacterial composition in the intestine ${ }^{(40)}$. Also noteworthy is that in a systematic review of the literature red and processed meat has been related to type $2 \mathrm{DM}$ in a number of large cohort studies ${ }^{(41)}$. The top contributors to market protein in our study population were red and processed meats, which contain nitrates and nitrites that are absent in TF.

Inuit $\mathrm{TF}$ differs from market food in that it provides beneficial nutrient exposures, being a rich source of longchain $n-3$ fatty acids and antioxidants ${ }^{(42)}$; an evaluation of which goes beyond the scope of the current paper. Also, the type of amino acids present in TF and market food protein sources may be important given the observation that cod protein improved insulin sensitivity in insulinresistant men $^{(43)}$. The finding that carbohydrate below the AMDR was associated with greater risk of glucose intolerance cannot be disentangled from \% $\mathrm{E}$ from protein, given the strong inverse correlation between the two macronutrients $(r=-0 \cdot 65)$. The mechanisms by which cholesterol may play a role in glucose intolerance are not known ${ }^{(26)}$, but could be partly attributed to the correlation between animal protein and cholesterol $(r=0.345)$. However, when we entered cholesterol in the same model with \%E from protein, the effect of cholesterol remained stable and significant and diagnostic tests indicated no collinearity problems.

The current finding that \%E from TF was associated with a near significant lower risk for glucose intolerance is compatible with reports from Alaska and Greenland which investigated the association between fatty acid status and type $2 \mathrm{DM}^{(5,44-46)}$ but contradicts another from Greenland that found higher glucose intolerance with TF intake ${ }^{(47)}$. Another report from Greenland found that intakes of fruits and seal meat were negatively associated with the risk of diabetes $^{(3)}$.

\section{Limitations}

The study, however, is not without its limitations. The study population showed a mild degree of under-reporting of EI overall. Another limitation is that in all observational studies extremes in one dietary exposure variable can be related to extremes in other dietary exposures. Thus, in our observational study, one must interpret the data with caution as the overall findings speak to the potential deleterious aspect of unbalanced diets and cannot provide definitive evidence related to any specific nutrient exposure.

Another limitation of the dietary assessment is the reliance upon one $24 \mathrm{~h}$ recall in a relatively small study population. This may explain why the fibre intake in our population, which was very low for the majority of participants, did not reach statistical significance in its association with glucose intolerance. The time-consuming and comprehensive nature of the health survey precluded the use of repeated $24 \mathrm{~h}$ recalls, $24 \mathrm{~h}$ urinary nitrogen or a comprehensive and detailed FFQ given survey logistics and efforts to minimize research burden for study participants. Finally, the cross-sectional study design precludes the ability to rule out the possibility of reverse causation.

\section{Conclusion}

Nutrition transition continues throughout the Arctic and coincides with many cultural and built infrastructure changes that influence psychosocial stress and lifestyle behaviours which have consequences for an epidemiological transition of increased obesity and chronic diseases. The current study, based upon the rank ordering of study participants based upon one $24 \mathrm{~h}$ dietary recall, suggests that high cholesterol and protein intakes are associated with glucose intolerance among Inuit.

Further research is needed to elucidate beneficial and deleterious mediators within diets and their doseresponse effects. Knowledge translation activities and other measures to combat obesity and to improve dietary quality are needed to prevent the emergence of cardiometabolic diseases in the Canadian Arctic.

\section{Acknowledgements}

Acknowledgements: The authors wish to thank Dr Stan Kubow, Dr Nelofar Sheikh, Donna Leggee and Helga Saudny for their guidance and/or contribution to data collection and management. Financial support: This work was supported by the Canadian Federal Program for International Polar Year, Canadian Institutes for Health Research, Canada Research Chair Program, Canadian Foundation for Innovation, Health Canada, Indian and Northern Affairs, Government of Nunavut and ArcticNet. The funders had no role in the design, analysis or writing of this article. Conflict of interest: None. Authorship: S.S. and L.J.-D. analysed the data and wrote the manuscript; T.K.Y. and G.M.E. designed and conducted the study, supervised data analyses, guided interpretation of the results, and edited and wrote the manuscript. Ethics of human subject participation: This study was conducted according to the guidelines laid down in the Declaration of Helsinki and all procedures involving human subjects/patients were approved by the McGill University Institutional Review Board. Written consent was obtained from all subjects/patients.

\section{References}

1. Mouratoff GJ, Carroll NV \& Scott EM (1967) Diabetes mellitus in Eskimos. JAMA 199, 107-112. 
2. Egeland GM, Cao Z \& Young TK (2011) Hypertriglyceridemic-waist phenotype and glucose intolerance among Canadian Inuit: the International Polar Year Inuit Health Survey for Adults 2007-2008. CMAJ 183, E553-E558.

3. Jorgensen ME, Bjeregaard P \& Borch-Johnsen K (2002) Diabetes and impaired glucose tolerance among the inuit population of Greenland. Diabetes Care 25, 1766-1771.

4. Young TK, Reading J, Elias B et al. (2000) Type 2 diabetes mellitus in Canada's First Nations: status of an epidemic in progress. CMAJ 163, 561-566.

5. Ebbesson SO, Risica PM, Ebbesson LO et al. (2005) Omega3 fatty acids improve glucose tolerance and components of the metabolic syndrome in Alaskan Eskimos: the Alaska Siberia project. Int J Circumpolar Health 64, 396-408.

6. Kuhnlein HV, Soueida R \& Receveur O (1996) Dietary nutrient profiles of Canadian Baffin Island Inuit differ by food source, season, and age. J Am Diet Assoc 96, 155-162.

7. Popkin BM \& Gordon-Larsen P (2004) The nutrition transition: worldwide obesity dynamics and their determinants. Int J Obes Relat Metab Disord 28, Suppl. 3, S2-S9.

8. Sheikh N, Egeland GM, Johnson-Down L et al. (2011) Changing dietary patterns and body mass index over time in Canadian Inuit communities. Int J Circumpolar Health 70, 511-519.

9. Egeland GM, Johnson-Down L, Cao ZR et al. (2011) Food insecurity and nutrition transition combine to affect nutrient intakes in Canadian Arctic communities. J Nutr 141, 1746-1753.

10. de Koning L, Fung TT, Liao X et al. (2011) Lowcarbohydrate diet scores and risk of type 2 diabetes in men. Am J Clin Nutr 93, 844-850.

11. de Koning L, Malik VS, Rimm EB et al. (2011) Sugarsweetened and artificially sweetened beverage consumption and risk of type 2 diabetes in men. Am J Clin Nutr $\mathbf{9 3}$, 1321-1327.

12. Micha R \& Mozaffarian D (2010) Saturated fat and cardiometabolic risk factors, coronary heart disease, stroke, and diabetes: a fresh look at the evidence. Lipids 45, 893-905.

13. Rosanoff A, Weaver CM \& Rude RK (2012) Suboptimal magnesium status in the United States: are the health consequences underestimated? Nutr Rev 70, 153-164.

14. Wolever TM, Hamad S, Gittelsohn J et al. (1997) Low dietary fiber and high protein intakes associated with newly diagnosed diabetes in a remote aboriginal community. Am J Clin Nutr 66, 1470-1474.

15. Beletate V, El Dib RP \& Atallah AN (2007) Zinc supplementation for the prevention of type 2 diabetes mellitus. Cochrane Database Syst Rev issue 1, CD005525.

16. Alhazmi A, Stojanovski E, McEvoy M et al. (2012) Macronutrient intakes and development of type 2 diabetes: a systematic review and meta-analysis of cohort studies. $J$ Am Coll Nutr 31, 243-258.

17. Alhazmi A, Stojanovski E, McEvoy M et al. (2014) The association between dietary patterns and type 2 diabetes: a systematic review and meta-analysis of cohort studies. J Hum Nutr Diet 27, 251-260.

18. Spence M, McKinley MC \& Hunter SJ (2010) Session 4: CVD, diabetes and cancer: diet, insulin resistance and diabetes: the right (pro)portions. Proc Nutr Soc 69, 61-69.

19. Nathan DM, Davidson MB, DeFronzo RA et al. (2007) Impaired fasting glucose and impaired glucose tolerance: implications for care. Diabetes Care 30, 753-759.

20. Slein MW (1963) Methods of Enzymatic Analysis. New York: Academic Press.

21. World Health Organization (2000) Obesity: Preventing and Managing the Global Epidemic. Report of a WHO Consultation. WHO Technical Report Series no. 894. Geneva: WHO; available at http://www.who.int/nutrition/publications/ obesity/WHO_TRS_894/en
22. Alberti KGMM, Zimmet P \& Shaw J (2006) Metabolic syndrome - a new world-wide definition. A Consensus Statement from the International Diabetes Federation. Diabet Med 23, 469-480.

23. American Council on Exercise (2009) What are the guidelines for percentage of body fat loss? Ask the Expert Blog, 2 December. http://www.acefitness.org/acefit/healthy-livingarticle/60/112/what-are-the-guidelines-for-percentage-ofbody-fat (accessed October 2015).

24. Sakamoto Y, Nishizawa M, Sato H et al. (2002) International comparison: resting energy expenditure prediction models. Am J Clin Nutr 75, 358S-359S.

25. Craig CL, Marshall AL, Sjostrom M et al. (2003) International physical activity questionnaire: 12-country reliability and validity. Med Sci Sports Exerc 35, 1381-1395.

26. Meyer KA, Kushi LH, Jacobs DR et al. (2001) Dietary fat and incidence of type 2 diabetes in older Iowa women. Diabetes Care 24, 1528-1535.

27. Health Canada (2007) Canadian Nutrient File. http:// www.hc-sc.gc.ca/fn-an/nutrition/fiche-nutri-data/cnf_aboutusaproposdenous_fcen-eng.php (accessed June 2015).

28. Willett WC (1998) Nutritional Epidemiology, 2nd ed. New York: Oxford University Press.

29. Amery A, Berthaux P, Bulpitt C et al. (1978) Glucose intolerance during diuretic therapy. Results of trial by the European Working Party on Hypertension in the Elderly. Lancet 1, 681-683.

30. Gibson RS (2005) Principles of Nutritional Assessment. New York: Oxford University Press.

31. Institute of Medicine, Food and Nutrition Board (2005) Dietary Reference Intakes for Energy, Carbohydrate, Fiber, Fat, Fatty Acids, Cholesterol, Protein, and Amino Acids (Macronutrients). Washington, DC: National Academies Press.

32. Gannon MC \& Nuttall FQ (2004) Effect of a high-protein, low-carbohydrate diet on blood glucose control in people with type 2 diabetes. Diabetes 53, 2375-2382.

33. Tinker LF, Sarto GE, Howard BV et al. (2011) Biomarkercalibrated dietary energy and protein intake associations with diabetes risk among postmenopausal women from the Women's Health Initiative. Am J Clin Nutr 94, 1600-1606.

34. Sluijs I, Beulens JW, van der A DL et al. (2010) Dietary intake of total, animal, and vegetable protein and risk of type 2 diabetes in the European Prospective Investigation into Cancer and Nutrition (EPIC)-NL study. Diabetes Care 33, 43-48.

35. Mannisto S, Kontto J, Kataja-Tuomola M et al. (2010) High processed meat consumption is a risk factor of type 2 diabetes in the Alpha-Tocopherol, Beta-Carotene Cancer Prevention study. Br J Nutr 103, 1817-1822.

36. Lee DH, Folsom AR \& Jacobs DR Jr (2004) Dietary iron intake and type 2 diabetes incidence in postmenopausal women: the Iowa Women's Health Study. Diabetologia 47, 185-194.

37. Rajpathak S, Ma J, Manson J et al. (2006) Iron intake and the risk of type 2 diabetes in women: a prospective cohort study. Diabetes Care 29, 1370-1376.

38. Fernandez-Cao JC, Arija V, Aranda N et al. (2013) Heme iron intake and risk of new-onset diabetes in a Mediterranean population at high risk of cardiovascular disease: an observational cohort analysis. BMC Public Health 13, 1042.

39. Jiang R, Ma J, Ascherio A et al. (2004) Dietary iron intake and blood donations in relation to risk of type 2 diabetes in men: a prospective cohort study. Am J Clin Nutr 79, 70-75.

40. Le Leu RK, Brown IL, Hu Y et al. (2007) Effect of dietary resistant starch and protein on colonic fermentation and intestinal tumourigenesis in rats. Carcinogenesis 28, 240-245.

41. Micha R, Wallace SK \& Mozaffarian D (2010) Red and processed meat consumption and risk of incident coronary heart disease, stroke, and diabetes mellitus: a systematic review and meta-analysis. Circulation 121, 2271-2283. 
42. Hansen JC, Deutch B, Pedersen HS et al. (2004) Selenium status in Greenland Inuit. Sci Total Environ 331, 207-214.

43. Ouellet V, Marois J, Weisnagel SJ et al. (2007) Dietary cod protein improves insulin sensitivity in insulin-resistant men and women. Diabetes Care 30, 2816-2821.

44. Ebbesson SO, Kennish J, Ebbesson L et al. (1999) Diabetes is related to fatty acid imbalance in Eskimos. Int Circumpolar Health 58, 108-119.

45. Ebbesson SO, Tejero ME, López-Alvarenga JC et al. (2010) Individual saturated fatty acids are associated with different components of insulin resistance and glucose metabolism: the GOCADAN study. Int J Circumpolar Health 69, 344-351.

46. Thorseng T, Witte DR, Vistisen D et al. (2009) The association between $n-3$ fatty acids in erythrocyte membranes and insulin resistance: the Inuit Health in Transition Study. Int J Circumpolar Health 68, 327-336.

47. Jeppesen C, Bjerregaard P \& Jørgensen ME (2014) Dietary patterns in Greenland and their relationship with type 2 diabetes mellitus and glucose intolerance. Public Health Nutr 17, 462-470. 